\title{
MJN COPING BEHAVIORS IN CLINICAL PRACTICE AMONG NURSING STUDENTS
}

\author{
Tan Yu Chin 1 , Chang Woan Ching ${ }^{2 *}$, Yee Bit-Lian² \\ ${ }^{1}$ Assunta Hospital, Selangor, Malaysia \\ ${ }^{2}$ International Medical University, Kuala Lumpur, Malaysia \\ *Corresponding Author's Email: ChangWoanChing@imu.edu.my
}

\begin{abstract}
Background: Coping is an alleviating factor that could assist individuals to balance psychosocial adaptation during a stressful event. Nurses perceived stress during clinical practice can be controlled using coping mechanism. Purpose: This study aims to identify the perception of coping behaviors among student nurses in clinical practice at a private nursing college, Selangor. Methods: This is a cross-sectional, quantitative, descriptive study. A simple random sampling method was employed in this study. A self-administered questionnaire, Coping Behaviors Inventory (CBI) was used to measure coping behavior among nursing students. A total of 145 students participated in the survey. Results: Findings of the study revealed that overall coping behavior of student nurses was moderate $(\mathrm{M}=3.34, \mathrm{SD}=0.55)$. The preferred coping behaviors reported by students include transference behavior $(\mathrm{M}=3.84, \mathrm{SD}=0.89)$, Problem solving behavior $(\mathrm{M}=3.75, \mathrm{SD}=0.46)$, optimistic behavior $(\mathrm{M}=3.35, \mathrm{SD}=0.53)$ and avoidance behaviors $(\mathrm{M}=2.44, \mathrm{SD}=0.58)$. There was no significant difference between demographic variables (age, gender, and semester of clinical training) and overall coping behaviors among student nurses. However, there was a statistically significant difference between age and transference behavior, gender and problem-solving behavior, and semester and optimistic behavior. Conclusion: Nursing educators play a vital role to understand students' coping behaviors, and to provide them guidance to cope better in the clinical settings.
\end{abstract}

Keywords: Perception, Coping Behaviors, Nursing Students

\section{INTRODUCTION}

Coping behavior is a natural response of a person to stress. The capability to cope is the main characteristic for nursing students to adjust and manage their stress (Hamaideh, Al-Omari \& Al-Modallal, 2017). Stress can be controlled by applying the correct coping method to reduce negative thoughts, i.e., worries, loneliness, and anxiety. It is imperative for nursing students to be able to apply own coping mechanism to face stress during clinical practice. At the proposed study site, nursing students reported a high level of stress to achieve the targeted competency percentage set for core skills. A majority of nursing students lack in confidence to care for patients. A supportive environment is therefore crucial for nursing students to build their knowledge and skill competencies during clinical practice. Understanding how student nurses cope better to overcome their stress in the clinical settings is significant to promote more competent nurses in future.

Past literature (Ahmed \& Mohammed, 2019; Chen \& Hung, 2014; Hamaideh, Al-Omari \& Al-Modallal, 2017; Shaban, Akhu-Zaheya \& Khater, 2014) reported that problem-solving was the most commonly used coping method by nursing students during their clinical practice. Accordingly, majority of the nursing students were able to manage their stress with positive coping behaviors. In contrast, Chan, So \& Fong (2009), and Singh, Sharma \& Sharma (2011) indicated that most of the student nurses choose to use avoidance and transference behaviors as their coping mechanism to address stress in clinical practicum. Avoidance behavior refers to the intention of an individual to avoid a stressful situation (Hamaideh, Al-Omari \& Al-Modallal, 2017). While transferring behavior refers to individual's intention to divert oneself from a stressful situation (Hamaideh, Al-Omari \& Al-Modallal, 2017). Frequent 
use of avoidance and transferring behaviors could lead to poorer physical, psychological and social health among students (Gurkova \& Zelenikova, 2018; Labrague et al., 2018). In a recent study, Latif \& Nor (2019) found that religion practice is another commonly used coping strategy by Malaysian students. Majority of the students self-reported having positive coping behaviors.

According to Hamaideh, Al-Omari \& Al-Modallal (2017), nursing students those who did not stay with families $(t=2.048, p=0.043)$ applied positive coping behaviors compared to students who are staying with families. Another study by Labrague et al. (2018b) revealed a significant positive correlation between coping behaviors and age $(r=0.224 ; p<0.001)$, gender $(r=2.343$, $p=0.020$ ). It is essential for nursing students to know their own coping behaviors while managing with stress in order to prevent negative consequences that could affect nursing professionalism and personal attribute.

Although coping is a continuous process that comes along with stress; there is no specific requirement for one to set a fixed coping behavior. Nursing students should be orientated well in terms of ward management, hospital settings and policies prior to each clinical posting. Nursing educators, tutors and clinical instructors carry vital role to continuously support the student nurses; motivate them to poses positive coping behaviors in managing stress; and help them to identify learning needs for effective coping management (Ahmed \& Mohammed, 2019).

\section{Purpose of the study}

The purpose of the study is to identify the perception of coping behavior during clinical practice among nursing students in a private nursing college in Selangor.

\section{Research questions}

1. What is the perception of coping behavior in clinical practice among nursing students?

2. Is there any difference between demographic variables (age, gender, semester) and coping behaviors in clinical practice among nursing students?

\section{METHODOLOGY}

A cross-sectional, quantitative and descriptive study was employed in this study. The targeted population were 200 nursing students from a private nursing college in Selangor. A simple random sampling method was used to ensure equal chance of participation of sample for the study. Estimated sample size required was 132 based on Raosoft calculator, with 5\% of margin error, $95 \%$ of the confidence interval, and $50 \%$ of the distribution rate. The targeted sample size required was 145 after a $10 \%$ attrition rate was added. The inclusion criteria for sample study includes nursing students from semester two to six, and with at least 4 weeks of clinical posting exposure. The exclusion criteria were nursing students who have yet to complete semester one and have less than 4 weeks clinical posting.

A self-administered questionnaire, Coping Behavior Inventory (CBI) was adopted with permission from Hamaideh, Al-Omari \& Al-Modallal (2017). The CBI tool consists of 17 items which include four types of behaviors: transference behavior, Problem solving behavior, optimistic behavior and avoidance behaviors. The CBI tool is using a 5-point Likert scale ranging from 1 , strongly disagree to 5 , strongly agree, to measure perception of coping behavior among student nurses. The higher the score of the CBI, the higher the coping behaviors perceived by nursing students.

A panel of three experts including two nursing tutors and a clinical instructor were invited to validate the questionnaires. All the experts have at least five years' experience and expertise in clinical supervision and mentoring of student nurses. Minor amendment to the items was done based on comments from the panel of experts. Nevertheless, the original meaning of the construct remains unchanged. Thirty nursing students were employed for a pilot study. All of them were excluded from the main data collection. Cronbach's Alpha value of 0.733 was achieved to indicate the acceptable level of internal consistency of the CBI tool for the study.

\section{Data analysis}

A total of 145 student nurses participated in the study. Data were analysed using the Statistical Packages for the Social Sciences (SPSS) version 25. Descriptive statistics like frequency, mean, percentage and standard deviation were used to analyse the demographic data. Normality of the dependent variable is assumed in this study. Hence, the differences between demographics variables (age group, gender) and coping behaviors were tested using $T$-test, while ANOVA test was used to test the differences between semesters and coping behavior.

\section{RESULTS}

Table 1 shows that majority of the participants were aged between 8 to 22 years $(n=119,82.1 \%)$, with a mean age of 
20 years. Most of the student nurses are female $(\mathrm{n}=129$, $89 \%)$ and only $11 \%(\mathrm{n}=16)$ are male. The distribution of ethic group among the students includes Indian (29\%), Sabahan (20\%), Sarawakian (17.9\%), Chinese (15.2\%), Malay (12.4\%) and others (5.5\%). In terms of semester, the percentage of student nurses in each semester ranged between $23 \%$ to $26 \%$. Student nurses from semester 3 were excluded from participation as they were away in clinical posting.

Table 1: Descriptive Analysis on Demographic Data of Participants $(n=145)$

\begin{tabular}{|c|c|c|c|c|}
\hline Variables & $\begin{array}{l}\text { Frequency } \\
\text { (f) }\end{array}$ & $\begin{array}{c}\text { Percentage } \\
(\%)\end{array}$ & $\begin{array}{c}\text { Mean } \\
(\mathrm{M})\end{array}$ & $\begin{array}{c}\text { Standard } \\
\text { Deviation (SD) }\end{array}$ \\
\hline $\begin{array}{l}\text { Age } \\
18-22 \\
\geq 23\end{array}$ & $\begin{array}{c}119 \\
26\end{array}$ & $\begin{array}{l}82.1 \\
17.9\end{array}$ & 20.34 & 2.26 \\
\hline $\begin{array}{l}\text { Gender } \\
\text { Male } \\
\text { Female }\end{array}$ & $\begin{array}{c}16 \\
129 \\
\end{array}$ & $\begin{array}{l}11 \\
89 \\
\end{array}$ & & \\
\hline $\begin{array}{l}\text { Ethnicity } \\
\text { Malay } \\
\text { Chinese } \\
\text { Indian } \\
\text { Sabahan } \\
\text { Sarawakian } \\
\text { Other }\end{array}$ & $\begin{array}{c}18 \\
22 \\
42 \\
29 \\
26 \\
8\end{array}$ & $\begin{array}{c}12.4 \\
15.2 \\
29 \\
20 \\
17.9 \\
5.5\end{array}$ & & \\
\hline $\begin{array}{l}\text { Semester } \\
\text { Semester } 2 \\
\text { Semester } 4 \\
\text { Semester } 5 \\
\text { Semester } 6\end{array}$ & $\begin{array}{l}38 \\
34 \\
38 \\
35\end{array}$ & $\begin{array}{l}26.2 \\
23.4 \\
26.2 \\
24.1\end{array}$ & & \\
\hline
\end{tabular}

The findings of the study revealed that overall coping behavior among nursing students was at moderate level $(\mathrm{M}=3.34, \mathrm{SD}=0.55)$. The highest coping behavior reported was transference behaviors $(\mathrm{M}=3.84$, $\mathrm{SD}=0.89)$ followed by problem solving behavior $(\mathrm{M}=3.75, \mathrm{SD}=0.46)$, optimistic behavior $(\mathrm{M}=3.35$, $\mathrm{SD}=0.53)$ and avoidance behaviors $(\mathrm{M}=2.44, \mathrm{SD}=0.58)$. The details of the result were shown in Table 2 .

Table 2: Mean and Standard Deviation of Coping Behavior among Student Nurses $(n=145)$

\begin{tabular}{|c|l|c|c|}
\hline Item & Coping Behavior Inventory & $\begin{array}{c}\text { Mean } \\
\text { (M) }\end{array}$ & $\begin{array}{c}\text { Standard } \\
\text { Deviation } \\
\text { (SD) }\end{array}$ \\
\hline 1 & $\begin{array}{l}\text { I always avoid difficulties during clinical } \\
\text { practice. }\end{array}$ & 2.63 & 0.97 \\
2 & I always avoid tutor and clinical instructor. & 1.94 & 0.79 \\
3 & I never quarrel with others and lose temper. & 3.06 & 1.21 \\
4 & I always expect miracles so one does not & 2.72 & 1.26 \\
& have to face difficulties. & & 0.79 \\
& I always expect others to solve the problem & 1.89 & 0.58 \\
\hline & Overall Avoidance behavior & 2.44 & 0.2 \\
\hline
\end{tabular}

\begin{tabular}{|c|c|c|c|}
\hline 1 & $\begin{array}{l}\text { I always adopt different strategies to solve } \\
\text { problems. }\end{array}$ & 3.89 & 0.64 \\
\hline 2 & $\begin{array}{l}\text { I always set up objectives to solve } \\
\text { problems. }\end{array}$ & 3.68 & 0.79 \\
\hline 3 & $\begin{array}{l}\text { I always make plans, list priorities and } \\
\text { solve stressful events. }\end{array}$ & 3.76 & 0.86 \\
\hline 4 & $\begin{array}{l}\text { I always find the meaning of stressful } \\
\text { incidents. }\end{array}$ & 3.66 & 1.00 \\
\hline 5 & $\begin{array}{l}\text { I always employ past experience to solve } \\
\text { problems. }\end{array}$ & 4.14 & 0.71 \\
\hline \multirow[t]{2}{*}{6} & $\begin{array}{l}\text { I always have confidence in performing as } \\
\text { well as senior classmates. }\end{array}$ & 3.37 & 0.95 \\
\hline & Overall Problem-solving Behavior & 3.75 & 0.46 \\
\hline 1 & $\begin{array}{l}\text { I always keep an optimistic and positive } \\
\text { attitude in dealing with everything in life. }\end{array}$ & 3.94 & 0.82 \\
\hline 2 & I always see things objectively. & 3.68 & 0.79 \\
\hline \multirow[t]{2}{*}{3} & I always cry, to feel moody, sad and helpless & 2.44 & 1.23 \\
\hline & Overall Optimistic Behavior & 3.35 & 0.53 \\
\hline 1 & $\begin{array}{l}\text { I always treat myself with good meals and } \\
\text { take a long sleep. }\end{array}$ & 3.87 & 1.15 \\
\hline 2 & $\begin{array}{l}\text { I always save more time to sleep and } \\
\text { maintain good health to face stress. }\end{array}$ & 3.68 & 1.16 \\
\hline 3 & $\begin{array}{l}\text { I always relax via watching TV, movies, a } \\
\text { shower or physical exercises (e.g. playing, } \\
\text { jogging). }\end{array}$ & 3.97 & 1.12 \\
\hline & Overall Transference Behavior & 3.84 & 0.89 \\
\hline & Overall Coping Behavior & 3.34 & 0.05 \\
\hline
\end{tabular}

The study showed that there was no significant difference between demographic variables (age, gender, semester) and overall coping behaviors among student nurses. However, as showed in Table 3, there is a significant difference between gender and problemsolving behavior $(p=0.08)$, age groups and transference behaviors $(p=0.033)$, and semesters and optimistic behavior $(p=0.01)$. Post-hoc comparisons using the Turkey HSD test indicated that the semester 2 was significantly different from semester $6(P=0.008)$, while semester 4 did not differ significantly from either semester 2,5 or 6 . That is, the semester 2 and semester 6 student nurses differ significantly in terms of their optimistic behavior.

Table 3: Inferential Test for the Difference Between Demographic Variable (Gender, Age, Semester) and Coping Behaviors $(n=145)$

\begin{tabular}{|l|l|c|c|c|}
\hline $\begin{array}{l}\text { Coping } \\
\text { Behavior }\end{array}$ & $\begin{array}{l}\text { Demographic } \\
\text { variable }\end{array}$ & $\begin{array}{c}\text { T- } \\
\text { test }\end{array}$ & ANOVA & Sig. \\
\hline $\begin{array}{l}\text { Problem- } \\
\text { Solving }\end{array}$ & $\begin{array}{l}\text { Male } \\
\text { Female }\end{array}$ & 2.68 & & $0.008^{*}$ \\
\hline Transference & $\begin{array}{l}18 \text { to 22 years old } \\
\geq 23 \text { years old }\end{array}$ & -2.15 & & $0.033^{*}$ \\
\hline Optimistic & $\begin{array}{l}\text { Semester } 2 \\
\text { Semester 4 } \\
\text { Semester 5 } \\
\text { Semester 6 }\end{array}$ & & 3.80 & $0.010^{*}$ \\
\hline$p<0.05$ & \multicolumn{2}{|l}{} \\
\hline
\end{tabular}




\section{DISCUSSION}

Demographic charecteristics of the student in terms of age (Shaban, Akhu-Zaheya \& Khater, 2014) and gender (Hamzah, Hassan \& Yusoff, 2011) of student nurses enrolled in the nursing programme is consistent to past studies in other counties. Majority of the respondents were aged within 18 to 22 years when they join nursing. The reason is because students are required to obtain secondary school qualification as the entry requirements for diploma in nursing programme. While, female respondents are still the dominant group in nursing fields in Malaysia as compared to male. This phenomenon is also similar to many other countries in globe.

The findings of the study concluded that overall coping behaviors reported by nursing students were at moderate level. Transference behavior was the most common coping behaviors applied by nursing students followed by problem solving behavior, optimistic behavior and the least was avoidance behaviors. The results are consistent with past studies by (Chan, So \& Fong, 2009; Singh, Sharma \& Sharma, 2011; Yamashita, Saito \& Takao, 2012; Zhao et al., 2015). These implied that nursing students at the study site prefer to apply convenience methods in coping with stress during their clinical practice. The possible explanation could be due to the psychosocial development of the student nurses. Majority of the student nurses are at young adulthood who tends to redirect their own feelings, desires and expectations to another person they trusted/loved. Young adults are exploring relationships with others for long-term commitments based on Erikson's psychosocial developmental stages (McLeod, 2018). Therefore, it is not surprising that for most of the student nurses are at the moderate level in coping, and they choose to use transference behavior as their therapeutic method to relieve their emotional stress.

On the other site, students reported the least on applying avoidance behavior. The finding is consistent with few studies which indicated a minority of the student nurses use ignorance and avoidance method to cope with difficulties (Shaban, Akhu-Zaheya \& Khater, 2014; Ahmed \& Mohammed, 2019). One possible reason may be due to good rapport between student nurses and nursing educators / staff nurses. They may have built good relationship during clinical posting that encourage students to seek advice and guidance from the nurse educators and senior staff nurses. Thus, majority of the student nurses choose not to run away from obstacles but will apply positive and convenient coping behaviors when they face challenges in the clinical settings.

The findings of the current study show no significant difference between demographic factors (age, gender, semester) and coping behaviors. This is consistent to past study by Hamaideh, Al-Omari \& AlModallal (2017); but contradicted by Labrague et al. (2018b) who reported a significant different result for the overall coping behaviors. Nevertheless, in this study, significant difference was found for the sub-behaviors, between age and transference behavior; gender and problem-solving behavior; and semester and optimistic behavior. One possible reason may be due to the demographic background of the students participated in the study. As supported by Chan, So \& Fong (2009), majority of the nursing students did not learn the appropriate way to adopt a suitable coping behavior. Hence, majority of the young adult female students tend to use convenient and simple form of coping method to manage their stress in clinical practice. Senior student nurses demonstrated to cope better as compared to younger nurses as they become more mature in terms of more exposure to clinical posting and seniority in semester. In summation it can be said that female student nurses who are older in age and senior in semester are prone to use transference behavior when facing challenges in clinical posting; they are more optimistic and capable to cope better.

Zhao et al. (2015) claim that increased level of selfefficacy is likely to motivate nursing students to adopt positive coping method during stress. It is recommended to add coping mechanism component in nursing curriculum to enhance self-efficacy level of nursing students. Nursing educators/tutors/clinical instructors play a major role to identify students in needs and encourage them to overcome their difficulties using positive coping behavior. Hence, the student nurses are more motivated when they are well supported in the clinical learning environment along with positive coping mechanism.

\section{CONCLUSION}

Stress reduction is depend on the effective use of appropriate coping method. The findings revealed that majority of the student nurses reported having a moderately positive behavior in coping. Future research is 
recommended to explore further the experiences of coping behaviors among nursing students across private and public institutions in Malaysia. Perspectives of nursing educator/clinical instructors are added value to understand their professional view regarding students' coping.

\section{Conflict of Interests}

The authors declare that they have no conflict of interest.

\section{ACKNOWLEDGMENT}

This article is extracted from a research project [ID: BN1/2019(PR-43)] approved by The IMU JointCommittee on Research and Ethics, International Medical University. We hereby express our genuine gratitude for their funding and support. Also, we would like to thank the student nurses who have participated in this study.

\section{REFERENCES}

Ahmed, W.A.M. \& Mohammed, B.M.A. (2019). Nursing students' stress and coping strategies during clinical training in KSA. Journal of Taibah University Medical Sciences, 14(2), pp 116-122.

Chan, C.K.L., So, W. K. W. \& Fong, D.Y.T. (2009). Hong Kong baccalaureate nursing students' stress and their coping strategies in clinical practice. Journal of Professional Nursing, 25(5), pp 307-313.

Chen, Y-W. \& Hung, C-H. (2014). Predictors of Taiwanese baccalaureate nursing students' physio-psycho-social responses during clinical practicum. Nurse Education Today, 34(1), pp 73-77.

Gurkova, E. \& Zelenikova, R. (2018). Nursing students' perceived stress, coping strategies, health and supervisory approaches in clinical practice: A Slovak and Czech perspective. Nurse Education Today, 65, pp 4-10.

Hamaideh, S.H., Al-Omari, H. \& Al-Modallal, H. (2017). Nursing students' perceived stress and coping behaviors in clinical training in Saudi Arabia. Journal of Mental Health, 26(3), pp 197-203

Hamzah, R., Hassan, I.I. \& Yusoff, M.S.B. (2011). Stressors and coping strategies during clinical practices among undergraduates nursing students in Universiti Sains Malaysia (USM). Malaysian Journal of Medical Sciences, 26(2), pp 88-98.

Labrague, L.J., McEnroe-Petite, D.M., Al Amri, M., Fronda, D.C. \& Obeidat, A. A. (2018). An integrative review on coping skills in nursing students: implications for policy making. International Nursing Review, 65(2), pp 279291.

Labrague, L.J., McEnroe-Petitte, D.M., Papathanasiou, I. V., Edet, O.B., Tsaras, K., Leocadio, M.C., Colet, P., Kleisiaris, C.F., Fradelos, E.C., Rosales, R.A., Santos-Lucas, K.V. \& Velacaria, P.I.T. (2018). Stress and coping strategies among nursing students: An international study. Journal of Mental Health, 27(5), pp 402-408.

Latif, R. \& Nor, M.Z. (2019). Stressors and coping strategies during clinical practice among diploma nursing students. Malays Journal Medical Science, 26(2), pp 88-98.

McLeod, S.A. (2018). Erik Erikson's stages of psychosocial development. Retrieved from: https://www. simplypsychology.org/Erik-Erikson.html

Shaban, I. A., Akhu-Zaheya, L.M. \& Khater, W. A. (2014). Sources of stress and coping behaviors in clinical practice among baccalaureate nursing students. International Journal of Humanities and Social Science, 4(6), pp 194-202.

Singh, C., Sharma, S. \& Sharma, R.K. (2011). Level of stress and coping strategies used by nursing interns. Nursing and Midwifery Research Journal, 7(4), pp 152-160.

Yamashita, K., Saito, M. \& Takao, T. (2012). Stress and coping styles in Japanese nursing students. International Journal of Nursing Practice, 18(5), pp 489-496.

Zhao, F-F., Lei, X-L., He, W., Gu, Y-H. \& Li, D-W. (2015). The study of perceived stress, coping strategy and selfefficacy of Chinese undergraduate nursing students in clinical practice. International Journal of Nursing Practice, 21(4), pp 401-409. 